\title{
ANALISA PERBEDAAN KINERJA TURBIN ANGIN TIPE SAVONIUS DENGAN SAVONIUS HELIUS
}

\section{COMPARISON ANALYSIS FOR PERFORMANCE SAVONIUS AND SAVONIUS HELIUS WIND TURBINE}

\author{
Yuli Prasetyo $^{1}$, Teuku Multazam² \\ ${ }^{1}$ Politeknik Negeri Madiun, Jl. Serayu No 84, Madiun, Jawa Timur, Indonesia. \\ ${ }^{2}$ Universitas Iskandar Muda, Banda Aceh, Provinsi Aceh, Indonesia.
}

E-mail: yuliprasetyo2224@pnm.ac.id

Diterima: 14/08/2019; Disetujui: 31/08/2019

\begin{abstract}
ABSTRAK
Kemajuan teknologi telah sampai pada penggunaan energi alternatif sebagai pengganti sumber energi utama. Pemanfaatan sumber energi terbarukan antara lain energi angin sebagai energi alternatif yang dipakai untuk membangkitkan energi listrik. Oleh karena itu, pada penelitian ini dirancang sebuah prototipe turbin angin dengan poros vertikal (Vetical Axis Wind Turbine) tipe Savonius dan Savonius Helius sebagai solusi pemenuhan listrik dengan pemanfaatan energi alternatif terbarukan. Tahap penelitian meliputi perencanaan, pembuatan prototipe, dan pengujian prototipe. Proses pengujian prototipe dilakukan dengan menggunakan variasi kecepatan angin sebesar $2 \mathrm{~m} / \mathrm{s}, 3 \mathrm{~m} / \mathrm{s}, 4 \mathrm{~m} / \mathrm{s}, 5 \mathrm{~m} / \mathrm{s}$ dan membandingkan kecepatan putaran (Rpm) antara tipe Savonius dengan tipe Savonius Helius. Hasilnya menunjukkan bahwa turbin angin tipe Savonius memiliki kecepatan putaran tertinggi sebesar 229,2 Rpm pada kecepatan angin $5,9 \mathrm{~m} / \mathrm{s}$ dan tidak dapat berputar pada kecepatan angin $2 \mathrm{~m} / \mathrm{s}$. Sedangkan tipe Savonius Helius dengan variasi sudut per-blade $22,5^{\circ}$ menunjukkan kecepatan putaran tertinggi sebesar 222,4 Rpm pada kecepatan angin 5,9 m/s dan paling rendah sebesar 47,8 Rpm pada kecepatan angin $2,0 \mathrm{~m} / \mathrm{s}$. Berdasarkan hasil tersebut, dapat disimpulkan bahwa turbin angin tipe Savonius Helius dengan variasi sudut per-blade $22,5^{\circ}$ mampu menghasilkan kecepatan putaran yang relatif tinggi dan dapat berputar pada kecepatan angin yang rendah.
\end{abstract}

Kata Kunci: Vertical Axis Wind Turbine, Savonius, Savonius Helius, Kecepatan putaran. 


\begin{abstract}
Technological advances have arrived at the use of alternative energy as a substitute for the main energy source. The use of renewable energy sources includes wind energy as an alternative energy used to generate electricity. Therefore, in this study a prototype of Savonius and Savonius Helius type vertical shaft wind turbines (Vetical Axis Wind Turbine) was designed as a solution for electricity fulfillment with the use of renewable alternative energy. The research phase includes planning, prototyping, and testing prototypes. The prototype testing process was carried out using variations in wind speed of $2 \mathrm{~m} / \mathrm{s}, 3 \mathrm{~m} / \mathrm{s}, 4 \mathrm{~m} / \mathrm{s}, 5 \mathrm{~m} / \mathrm{s}$ and comparing the rotational speed (Rpm) between Savonius types and Savonius Helius types. The results show that the Savonius type wind turbine has the highest rotational speed of 229.2 Rpm at $5.9 \mathrm{~m} / \mathrm{s}$ wind speed and cannot rotate at wind speeds of $2 \mathrm{~m} / \mathrm{s}$. While the Savonius Helius type with a variation of per-blade angle $22.5^{\circ}$ shows the highest rotational speed of 222.4 Rpm at wind speeds of $5.9 \mathrm{~m} / \mathrm{s}$ and the lowest at $47.8 \mathrm{Rpm}$ at wind speeds of $2.0 \mathrm{~m} / \mathrm{s}$. Based on these results, it can be concluded that the Savonius Helius type wind turbine with a $22.5^{\circ}$ per-blade angle variation is capable of producing relatively high rotation speeds and can rotate at low wind speeds.
\end{abstract}

Keywords: Vertical Axis Wind Turbine, Savonius, Savonius Helius, Speed of rotation. 


\section{PENDAHULUAN}

Bentuk turbin angin yang banyak digunakan adalah turbin angin sumbu horizontal, tetapi turbin angin sumbu vertikal bisa menjadi alternatif untuk menghasilkan energi listrik. Turbin angin vertikal memiliki self starting yang baik sehingga mampu memutar rotor walaupun kecepatan angin relatif rendah dan torsi yang dihasilkan relatif tinggi [1]. Turbin angin sumbu vertical dapat berputar secara efektif dengan dorongan angina dari segala arah, sehingga sangat cocok untuk daerah yang arah anginnya tidak menentu [2]. Turbin angin sumbu vertikal memiliki efisiensi yang kecil karena memanfaatkan gaya drag. Daya yang diperoleh berasal dari selisih antara gaya dua penggerak momen positif dan negatif yang terjadi pada rotor [3]. Turbin angin Savonius merupakan salah satu tipe turbin angin poros vertikal. Turbin ini memiliki bentuk dan kontruksi yang sederhana dan disusun menyerupai huruf " $\mathrm{S}$ ".

Penelitian terdahulu tentang turbin angin adalah penelitian oleh [4]. Penelitian ini mengenai turbin poros vertical dengan tipe blade helical. Penelitian ini mendapatkan rpm yang kurang maksimal. Kemudian penelitian oleh [5] tentang membuat turbin Savonius agar dapat menerima angin dengan maksimal. Peneliti menganalisa pengaruh perbedaan kecepataan angin terhadap putaran turbin dan perbandingan keluaran dari VAWT model "U" dan "L". Kemudian penelitian oleh [6] mengenai karakteristik turbin angin sumbu vertical tipe savonius helius.

Sesuai uraian di atas maka pada penelitian ini penulis menggunakan turbin angin vertikal menggunakan gabungan dari tipe Savonius dan Helix. Dengan turbin tipe Savonius dan Helix diharapkan dapat menghasilkan putaran dan torsi yang lebih efisien daripada penelitian sebelumnya. Hal tersebut mempertimbangkan rpm dan torsi yang sesuai dengan generator agar output generator bisa maksimal. Hal lain yang harus dipertimbangkan adalah penggunaan dari bahan yang mampu menerima angin semaksimal mungkin. Penelitian ini juga membandingkan kinerja dari turbin angin tipe savonius dengan turbin angin tipe savonius helius.

\section{METODE PENELITIAN}

\section{Vertical Axis Wind Turbin (VAWT)}

Gambar 1. merupakan turbin angin yang memiliki sumbu atau poros vertikal. Turbin angin poros vertikal ini sedikit berbeda dengan horizontal dilihat dari sumbu atau porosnya. Turbin angin jenis ini memiliki blade yang memanjang dari atas ke bawah. Dengan sumbu vertikal, generator, gearbox dan komponen lainnya dapat ditempatkan dengan permukaan tanah, sehingga memudahkan dalam hal perawatan. Namun, karena tempatnya tidak terlalu tinggi maka energi angin yang tersedia rendah. 


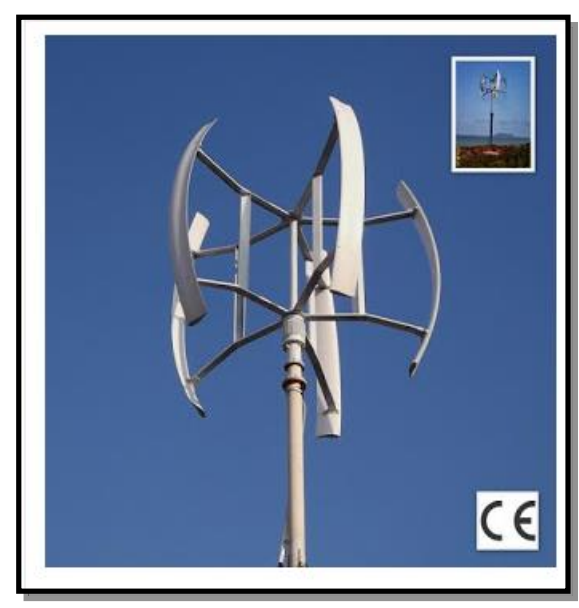

Gambar 1. Vertikal Axis Wind Turbine

Turbin angin jenis vertikal mempunyai beberapa tipe yang masing masing dari tipe tersebut memiliki ciri khas tersendiri. Berikut merupakan macam macam tipe Vertical Axis Wind Turbine (VAWT).

\subsection{Tipe Savonius}

Salah satu jenis turbin angin sumbu vertikal (VAWT) yang dapat digunakan pada angin berkecepatan rendah adalah tipe Savonius. Turbin ini ditemukan oleh sarjana Finlandia bernama Sigurd J.Savonius pada tahun 1922. Konstruksinya tersusun dari dua buah sudu setengah silinder. Pada perkembangannya turbin Savonius banyak mengalami perubahan bentuk rotor, seperti desain rotor berbentuk L.

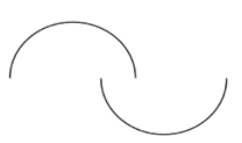

(a) Tipe U

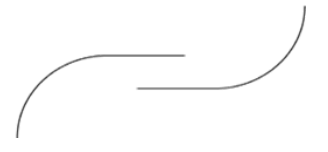

(b) Tipe L
Gambar 2. Desain Turbin Savonius Tipe U dan L
Angin yang berhembus dari salah satu bilah rotor diharapkan lebih banyak mengalir ke bilah rotor lainnya melalui celah di sekitar 5 poros sehingga menyediakan daya dorong tambahan pada bilah rotor ini, akibatnya rotor dapat berputar lebih cepat. Pada bentuk rotor Savonius setengah lingkaran (Savonius U), aliran udara di kedua sisi bilah sama besar, sementara pada rancangan kedua (Savonius L) aliran udara pada sisi bilah yang lurus lebih besar dibandingkan pada sisi bilah lengkung seperempat lingkaran (Soelaiman, 2006).

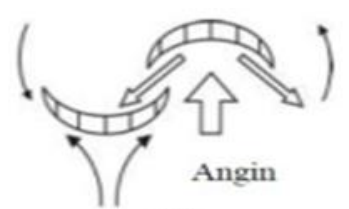

(a)

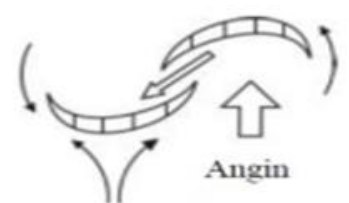

(b)

\section{Rotor Savonius U Rotor Savonius L}

Gambar 3. Perbedaan Angin pada Rotor Savonius

\subsection{Tipe Helical}

Dengan keunikan blade yang dimiliki oleh turbin angin vertikal tipe Helical ini, menjadikan turbin angin tipe tersebut banyak dikembangkan oleh Amerika Serikat. Bentuk blade yang dimiliki oleh turbin angin Helical ini dapat dilihat pada Gambar 4. Turbin tipe ini menggunakan dua buah blade dengan helical twist $90^{\circ}$ dengan bagian atas dan bawah memiliki bentuk yang sama, 


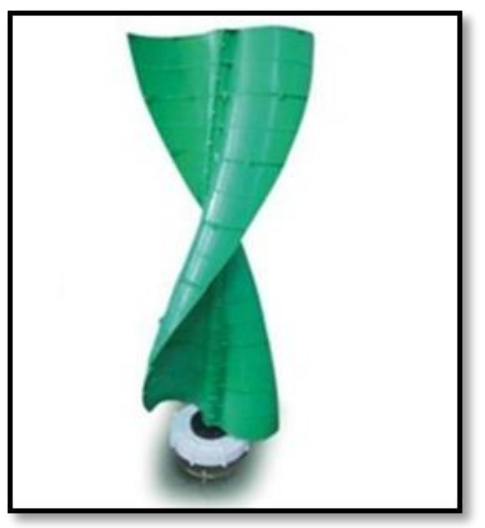

Gambar 4. Turbin Tipe Helical

\section{Desain Turbin}

Komponen utama dari turbin angin merupakan blade. Luas sapuan blade sangat berpengaruh terhadap kecepatan putaran (Rpm) yang dihasilkan oleh turbin. Semakin besar luas sapuan dari blade maka semakin besar pula Rpm yang dilhasilkan. Blade dibuat seperti gambar 5 karena jika angin menyapu daerah sapuan, angin ditampung oleh kelengkungan blade. Jika datar, maka angin yang mengenai blade tidak sepenuhnya ditampung. Dengan perbedaan sudut antara blade 1 dengan blade yang lain, maka sudut perputaran per blade dibuat sebesar $20^{0}$ diukur dari blade sebelumnya menjadi titik awal perubahan sudut blade yang ada di atasnya. Perubahan sudut blade seperti terlihat pada gambar 6 .

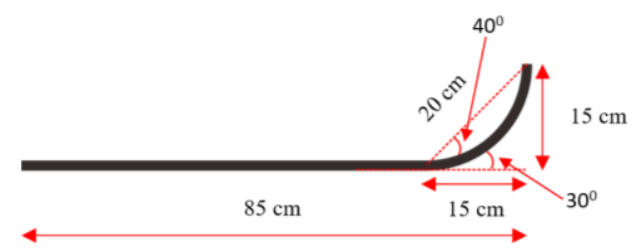

Gambar 5. Desain Blade Tampak dari Atas

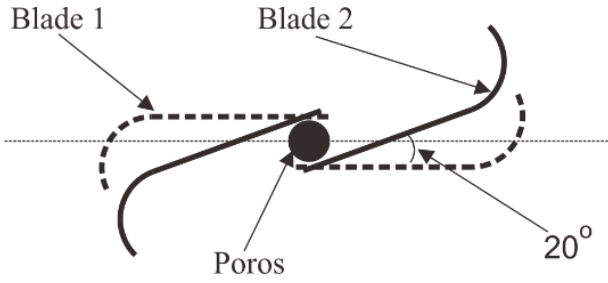

Gambar 6. Perubahan Sudut Blade

Desain keseluruhan dari turbin ini menggunakan kerangka balok dengan sisi atas yang tertutup untuk melindungi turbin dari air hujan untuk mencegah korosi pada poros dan bearing. Desain keseluruhan seperti terlihat pada gambar 7 .

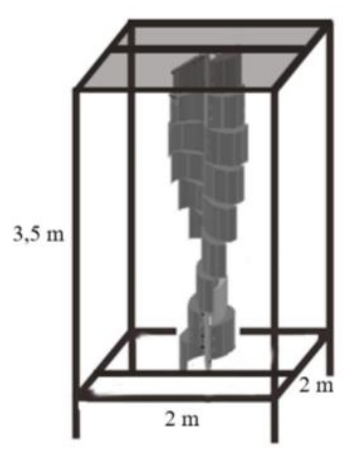

Gambar 7. Desain Turbin Secara Keseluruhan

\section{Diagram Alir Penelitian}

Diagram Alir dibuat bertujuan untuk memudahkan pembaca mengenai proses dari kerja sebuah alat penelitian ini. Pada gambar 8 dijelaskan bahwa dengan angin menerpa blade kemudian blade akan bergerak menyesuaikan arah angin. Saat blade bergerak dan menggerakkan poros utama, maka poros berputar yang di kopel dengan gearbox dan menghasilkan kecepatan putaran, kecepatan putaran diukur oleh tachometer. 


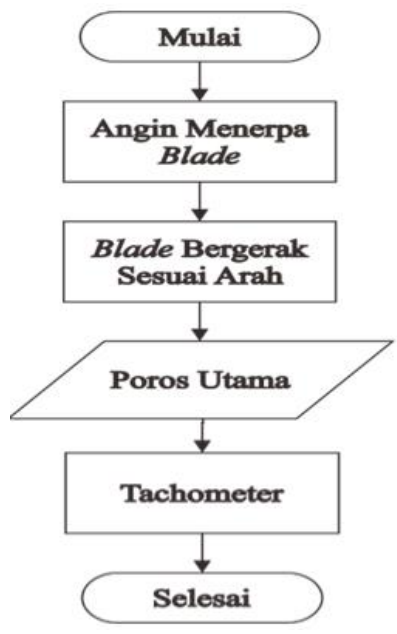

Gambar 8. Diagram Alir Cara Kerja Turbin

\section{HASIL PENELITIAN DAN PEMBAHASAN}

Pada tahap hasil dan pembahasan dilakukan pengujian pada alat untuk memperoleh data.

\section{1) Pengujian Alat Tipe Savonius}

Pada proses pengujian turbin angin tipe Savonius ini, blade dipasang sejajar dan tidak terdapat perbedaan sudut. Uji coba dilakukan dengan dua metode, yaitu menggunakan generator dan tanpa generator. Turbin angin tipe savonius terlihat seperti pada gambar 9. Kecepatan angin untuk pengujian antara $2 \mathrm{sampa} 5 \mathrm{~m} / \mathrm{s}$.

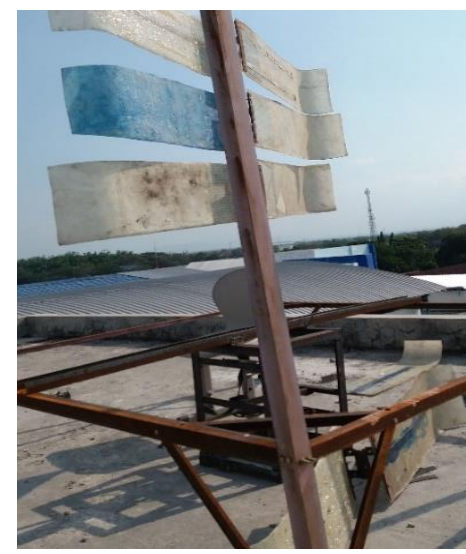

Gambar 9. Turbin Angin Tipe Savonius a. Tanpa Generator

Percobaan pertama turbin angin tipe Savonius dilakukan saat tanpa beban. Percobaan dilakukan dengan mengunakan blower sebagai input untuk mendapatkan angin yang stabil. Data hasil pengujian tanpa generator untuk turbin angin tipe Savonius terlihat seperti gambar 10.

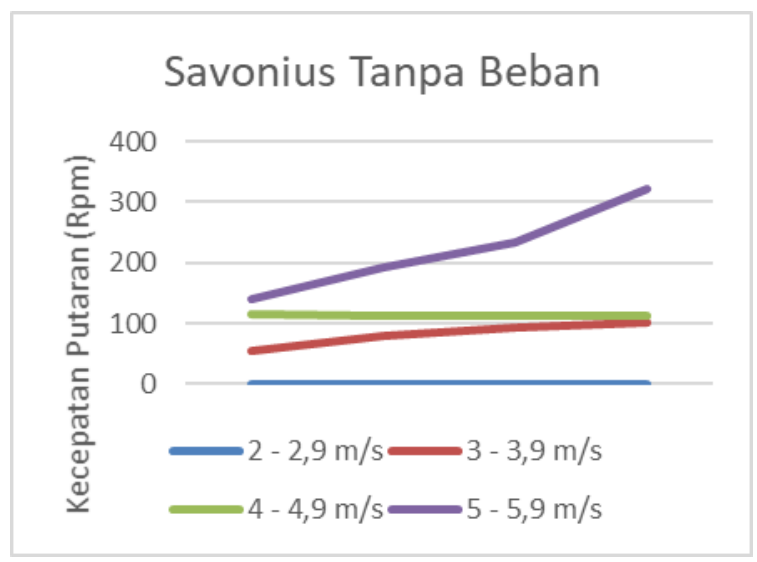

Gambar 10. Hasil Tipe Savonius Tanpa Generator

\section{b. Dengan Generator}

Pengujian menggunakan beban generator dilakukan dengan memasang generator pada poros sebagai beban. Hasil pengujian tipe Savonius dengan generator terdapat pada gambar 11 .

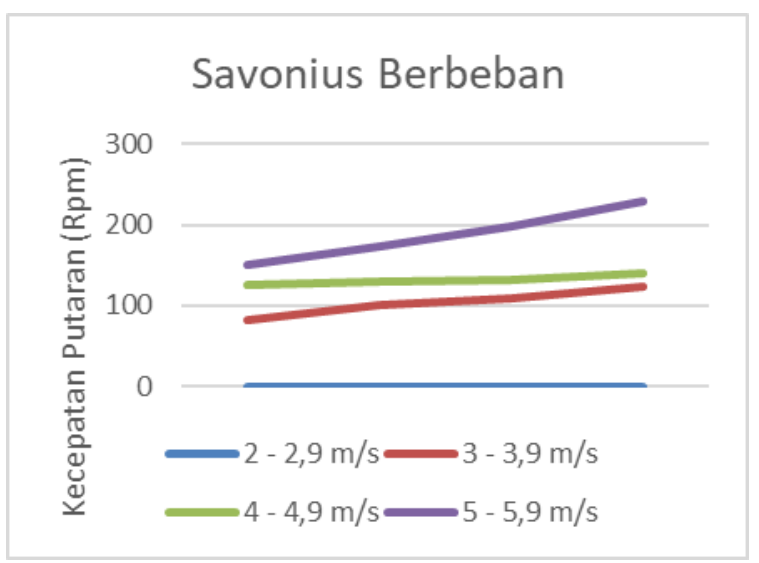

Gambar 11. Hasil Tipe Savonius Dengan Generator 


\section{2) Pengujian Alat Tipe Savonius Helius}

Proses pengujian selanjutnya dilakukan pada turbin angin tipe Savonius Helius. Pada tipe ini, antar blade diatur dengan variasi sudut sebesar $22,5^{\circ}$. Turbin angin tipe savonius helius terlihat seperti pada gambar 12 .

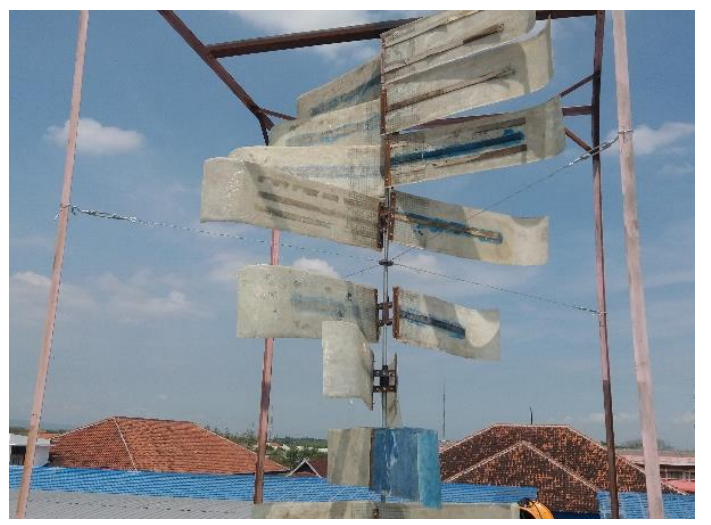

Gambar 12. Turbin Angin Tipe Savonius Helius

a. Tanpa Generator

Data hasil pengujian tanpa generator untuk turbin angin tipe Savonius Helius terlihat seperti gambar 13.

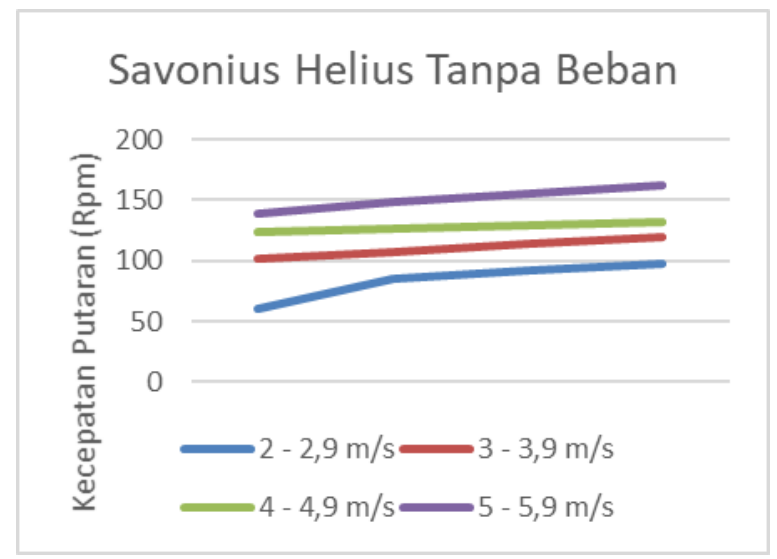

Gambar 13. Hasil Tipe Savonius Helius tanpa Generator

\section{b. Dengan Generator}

Data hasil pengujian dengan generator untuk turbin angin tipe Savonius Helius terlihat seperti gambar 14 .

\section{Savonius Helius Berbeban}

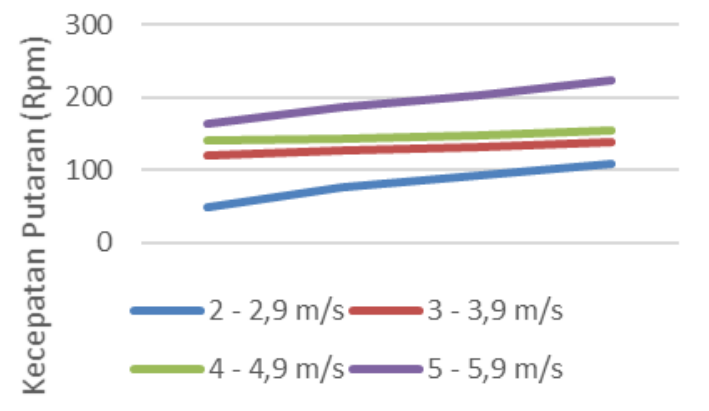

Gambar 14. Hasil Tipe Savonius Helius dengan Generator

\section{3) Hasil Perbandingan Pengujian Alat}

Hasil yang diperoleh dari pengujian turbin angin tipe Savonius dan tipe Savonius Helius dapat dibandingkan kecepatan putarannya dengan perbedaan kecepatan angin yang diatur pada setiap pengujian yang dilakukan. Perbandingan kecepatan putaran tipe Savonius dan tipe Savonius Helius terlihat seperti pada gambar 15.

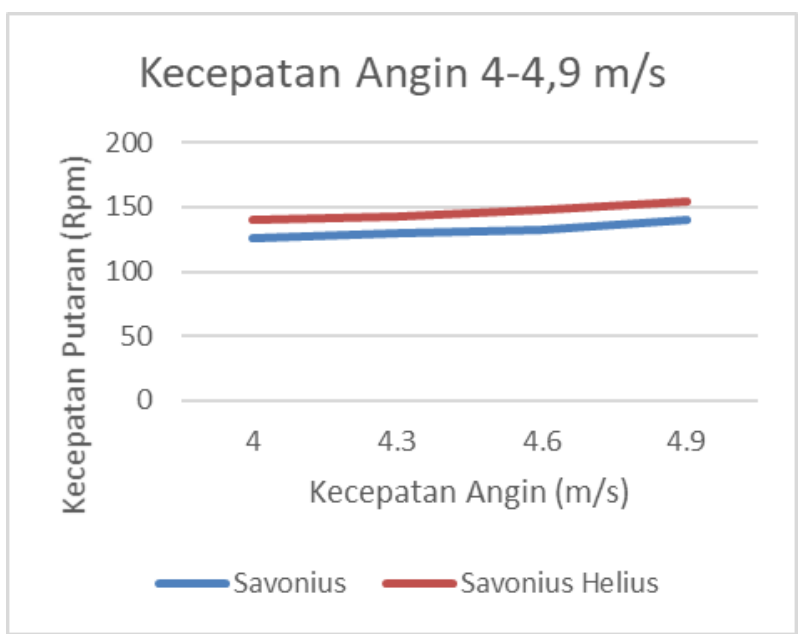

Gambar 15. Perbandingan Kecepatan Savonius dan Savonius Helius

Hasil pengujian yang telah diperoleh, diolah menjadi gambar yang menyajikan data tegangan yang dihasilkan oleh tipe Savonius 
dan Savonius Helius. Tegangan yang jelas pada perbedaan kecepatan putaran dan dihasilkan berupa tegangan AC dari tegangan AC yang dihasilkan. generator. Perbandingan antara hasil tegangan AC tipe Savonius dan Savonius Helius terlihat pada gambar 16.

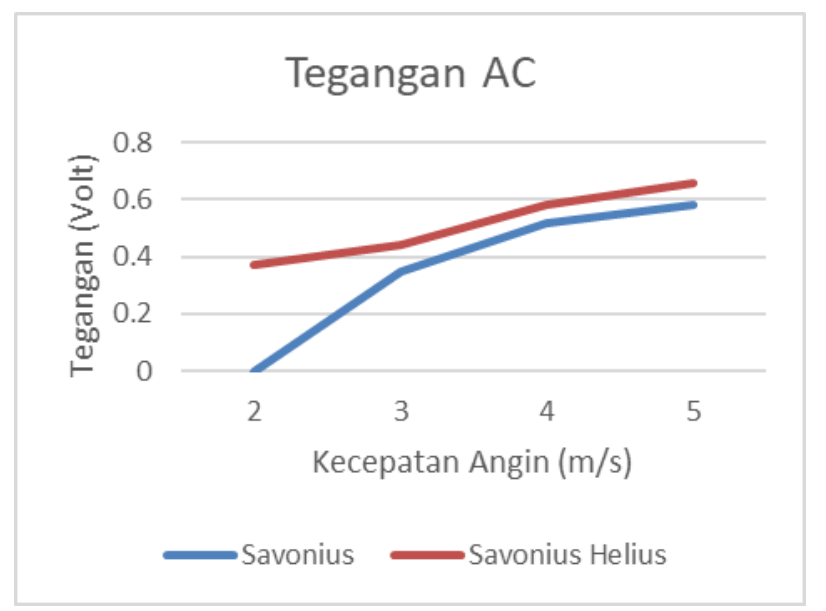

\section{KESIMPULAN}

Hasil yang dapat diambil dari penelitian ini adalah turbin angin dapat memutar rotor secara maksimal apabila lubang dan poros memiliki tingkat keakuratan yang tinggi. Perbandingan analisa kinerja dari dua tipe turbin angin ini adalah turbin angina tipe Savonius Helius dapat menghasilkan kecepatan putar yang relative tinggi dan mampu berputar pada kecepatan angin yang rendah daripada tipe Savonius.

Gambar 16. Perbandingan Tegangan AC Savonius dan Savonius Helius

Dari hasil perbandingan antara tipe Savonius dan tipe Savonius Helius terlihat

\section{DAFTAR PUSTAKA}

[1] Putra, M. Alexin dkk. 2011. Uji Experimental Rotor Helical Savonius Dibandingkan dengan Rotor Savonius. Seminar Nasional Teknik Mesin 6, Surabaya, 16 Juni 2011: 101-103

[2] Angkasa, Tauqit. 2016. Perancangan Turbin Heliks Vertikal dengan Jumlah Blade pada VAWT. Laporan Tugas Akhir, Politeknik Negeri Madiun

[3] Santoso, Tosy Purbo. 2017. Perancangan Turbin VAWT Model Savonius Cembung. Laporan Tugas Akhir, Politeknik Negeri Madiun

[4] Affifudin, M.A, dkk. 2010. Studi Eksperimental Performasi Vertical Axis Wind Turbine (VWAT) dengan Variasi Desain Turbin. Institut Teknologi Sepuluh Nopember.

[5] Latif, Melda. 2013. Efisiensi Prototipe Turbin Savonius pada Kecepatan Angin Rendah. Jurnal Rekayasa Elektronika, Vol.10, No. 3, April 2013:147-151

[6] Prasetyo, Yuli, dan H., Nur Asyik. 2019. Analisa Karakteristik Turbin Angin Sumbu Vertikal Tipe Savonius Helius. Journal of Electrical Electronic Control and Automotive Engineering (JEECAE), Vol. 4, No.1, Mei 2019. pp 241-244. 